\title{
MEMORIE VAN DEN AMERIKAANSCHEN RAAD OVER DE HOLLANDSCHE BEZITTINGEN IN WEST-INDIE IN JULI 1806 \\ DOOR
}

\author{
DR. J. DE HULLU
}

Archivaris aan het Algemeen Rijksarchief.

In zijn nota over de Nederlandsche bezittingen in WestIndië, op 2 September 1806 aan den minister van Koloniën aangeboden ${ }^{1}$ ), vermeldt de chef der Divisie West van het Departement van Koloniën Mr. J. C. van der Kemp, dat op 2 Juli van datzelfde jaar de Raad der Amerikaansche koloniën voor Koning Lodewijk Napoleon een gelijksoortige memorie had opgesteld, en dat hij met het oog hierop een oogenblik in twijfel had verkeerd of hij niet kon volstaan met eenvoudig naar die memorie te verwijzen. Maar ten slotte, zoo betuigt hij, had hij dit denkbeeld laten varen omdat de memorie meer strekte om den Koning een algemeen overzicht van onze West-Indische koloniën te geven dan om ,meer in het bijzonder het belang der verloren koloniën te doen kennen". Inderdaad vullen, gelijk men bij de kennisneming van beide gewaar zal worden, de nota en memorie elkander aan. Het schijnt derhalve niet van belang ontbloot ook deze laatste hier bekend te maken. - In de volgende bladzijden vindt men nu de memorie medegedeeld, niet in extenso echter, want daarvoor is zij veel te wijdloopig, maar in den vorm van een résumé, alleen bevattende wat van wezenlijk belang is.

In tegenstelling met andere natiën, wier Amerikaansche kolo-

1) Uitgegeven West-Indische Gids 1920 blz. 407 vlg. 


\section{MEMORIE OVER DE HOLLANDSCHE BEZITTINGEN.}

niën ,,in het opmaken van hare nationale ressources" slechts in de tweede plaats in aanmerking komen, moet Holland van zijn bezittingen in West-Indië en op de Kust van Guinee „de herstelling van zijn vervallen zaken zoo niet geheel en alleen althans voornamelijk" verwachten. Voorheen weliswaar toen de scheepvaart, negotie, nijverheid en de Oost-Indische handel derRepubliek zoo ontzaglijk bloeiden, kon men haar West-Indische koloniën beschouwen als „ressources van minder aanbelang”, ofschoon zelfs in dien tijd onze vaart en handel op West-Indië ,,een circulatie van 27 millioen veroorzaakte".

De Hollandsche bezittingen in West-Indië bestaan in handeldrijvende: St. Eustatius, Hollandsch St. Martin en Curaçao, en in landbouwende: Suriname, Berbice en Demerary. Die op de Kust van Guinee, zijn noch het een noch het ander, doch nemen een eigen plaats in.

De laatstgenoemde zijn gelegen in het ongezondste gedeelte van de wereld, zoodat velen van de derwaarts verplaatste Europeanen een prooi worden van het ongunstige klimaat. $\mathrm{Zij}$ bestaan niet in plantages of bebouwde landerijen doch in enkele grootere en kleinere forten, meer geschikt ter verdediging tegen de inboorlingen dan tegen een buitenlandschen vijand, met namen: Accra, Axem, Chama, Cormantijn, Hollandia, Accoda, Boutry, Taccorary, Saccondee, Commany, Mouree, Apam, Berkoe en St. George del Mina. Dit laatste fort, dat de zetel is van het bestuur, bevindt zich „volgens de laatste berichten in een zeer goeden staat". De verstandhouding tusschen de onzen en de negerbevolking is tot dusver zeer goed en ,dezelve gereed en genegen om een vijandelijken aanval te helpen afweren". De Europeesche krijgsmacht, aldaar in onzen dienst, is zeer gering, men heeft eenige weinige blanke onderofficieren en artilleristen daar altoos genoegzaam voor geoordeeld, de soldaten neemt men meest uit Tapoejers of inlanders. Het bestuur berust bij een gouverneur-generaal, vier eerste residenten op Accra, Axim, Cormantijn en Chama en negen tweede residenten op de overige forten, een secretaris, een boekhoudergeneraal, benevens eenige mindere beambten. Tezamen met enkele gepensioneerden en de militaire officieren en onderofficieren maken zij de eenige bevolking uit van blanken, die wanneer zij compleet is 60 maar thans nog geen 20 zielen telt. Met de tusschen onze forten in gelegen forten van de Denen en Engelschen zijn er „niettegenstaande den oorlog ${ }^{1}$ ) eenige wederzijdsche arrangementen om elkanders forten vrij te mogen passeeren en repassee-

1) De oorlog namelijk tusschen Holland en Engeland. 
ren, daar men te zwak is om oorlog te voeren en ook anderszins zonder noodzaak zichzelf zeer zoude benadeelen en aan de naturellen des lands wapenen in de hand geven om de Europeanen te beschadigen". Onze vestiging aldaar beoogt niet het drijven van handel met het binnenland van Afrika maar het verkrijgen van negerslaven voor onze West-Indische landbouwkoloniën, die alleen door gedurigen aanvoer van negers in stand kunnen blijven omdat voor het plantagewerk in die verzengde luchtstreek geen Europeesche arbeiders te gebruiken zijn. Daarvoor zal men dus onze etablissementen in Guinee moeten aanhouden, terwijl met den negerhandel daar te lande tevens gepaard kan gaan het inruilen van onze waren tegen ivoor, stofgoud, gommen, verfhout en dergelijke. De jaarlijksche bestuurskosten, tusschen de een en tweehonderd duizend gulden beloopende, worden bijgevolg weer goed gemaakt door onze West-Indische landbouwkoloniën. „Daar die negerhandel mitsdien op alle wijze moet worden gefavoriseerd en geen lasten betaalt zijn de inkomsten zeer gering en bestaan voornamelijk in de vertolling, welke de Portugeesche Brazilvaarders volgens oud costuum ${ }^{1}$ ), aan d'Elmina komende, doen van rollen tabak voor de cano's, die hun tot het drijven van handel met de naturellen des lands geleend worden." Nu tengevolge van den oorlog de Europeanen (behalve de Engelschen) zoo weinig op de kusten van Afrika varen, gaat de correspondentie met ons etablissement op Guinee hoogst ongeregeld. Ook zijn de Denen uiterst huiverig om daar personen en goederen voor mede te nemen. Men mag verwachten dat deze kolonie bij den vrede zich weer oprichten zal uit het diepe verval, waarin haar de sinds 1795 schier onafgebroken voortdurende oorlog heeft gestort.

Van de handeldrijvende volkplantingen in West-Indië bezit St. Eustatius geen haven, alleen een open, van alle zijden toegankelijke, reede. Het ,is mitsdien voor geen defensie vatbaar, gelijk de successieve oorlogen geleerd hebben wanneer het gedurig genomen en hernomen is"; de toegang tot de reede ware voor vijandelijke schepen alleen te beletten door middel van een groot aantal oorlogsschepen. Van wege zijn onvruchtbaren bodem bezit St. Eustatius voor ons uitsluitend waarde uit een handelsoogpunt beschouwd, wijl Holland ,in de Antilles geen andere possessie heeft" en omdat het in vredestijd een entrepôt vormt voor de Europeesche waren die, met Hollandsche schepen aangebracht, er worden verruild tegen West-Indische. Voorheen voeren er op dit eiland jaar in jaar uit 30 à 40 rijkgeladen schepen, ,,welker ge-

\footnotetext{
1) gewoonte.
} 


\section{MEMORIE OVER DE HOLLANDSCHE BEZITTINGEN.}

tal de Raad thans niet hooger dan op 20 durft stellen". Eénmaal zelfs bedroeg dit getal over de 100, namelijk in het begin van den oorlog tusschen de Vereenigde Staten en Engeland. „De populatie bestond in 1790 uit 2341 blanken, 385 lieden van de couleur, 258 vrije negers, 348 gecouleurde slaven en 4792 negerslaven", thans „maar uit 4 à 500 tot 700 negers en lieden van de couleur". Deze achteruitgang is veroorzaakt deels door den aanhoudenden oorlog deels „door de vexatoire handelingen van eenige Fransche commissarissen van Guadeloupe die, niettegenstaande de relatiën tusschen den Staat en Frankrijk toen reeds subsisteerden ${ }^{1}$ ), het eiland vijandelijk behandeld en van hetzelfde een contributie van 8000 Spaansche daalders 's maands hebben gevorderd tot het door de Engelschen is geoccupeerd ${ }^{2}$ ), waardoor veroorzaakt is dat alles wat verhuizen konde is verhuisd". Zonder twijfel echter zullen de uitgewekenen wel weder terugkeeren, zoodra er een bestendige vrede tot stand komt. Het gouvernement op St. Eustatius bestaat uit een gouverneur, eenige Raden uit de ingezetenen, een boekhouder-generaal en een secretaris; de militaire bezetting telt volgens de laatste rapporten 1 kapitein, 1 eerste en 2 tweede luitenants en 60 onderofficieren en soldaten. „De kolonie kost jaarlijks $f 50,000$ aan het moederland zonder dat die uitgaven door eenige noemenswaardige inkomsten in de koloniën verminderd worden of door eenige voordeelen gedurende de stremming der navigatie worden gecompenseerd."

Van St. Martin bezitten de Franschen verreweg de grootste helft. Van de bevolking, woont bijna de helft op het Hollandsche gedeelte, wier „possessiën voor het grootste gedeelte” in het Fransche gebied liggen. De van ouds bestaande „conventie van neutraliteit" tusschen de beide helften is in onbruik geraakt en dus ,kon het niet anders of er moesten van tijd tot tijd disputen ontstaan, welke de introductie van een nadere conventie noodig hebben gemaakt, gelijk de Raad dan ook is geïnformeerd dat er een nieuwe tusschen den kapitein-generaal Ernouf van Guadeloupe, onder wiens dependentie St. Martin behoort, ter eenre en den Hollandschen gouverneur Rink ter andere zijde is gesloten". De ruime baai, in het Hollandsche gedeelte, waar langs zich het dorp Philipsburg uitstrekt, levert onder de bescherming van de batterijen en het fort Gelderland een veilige schuilplaats op voor schepen, maar ,met dat al is de staat van

1) D. i. de Republiek reeds met Frankrijk in bondgenootschap was.

2 Het eiland werd aan de Franschen overgegeven op 16 April 1795, door de Engelschen in bezit genomen 16 April 1801. 
verdediging van geen groote consequentie" doordien „de vijand in andere baaien landen kan en het van zelfs spreekt dat, zoo het eiland defensie waardig wordt gekeurd, het plan daartoe gezamentlijk tusschen de chefs der Fransche en die der Hollandsche zou moeten worden geconcerteerd". De ingezetenen vinden hun onderhoud in: $1^{\circ}$. de suiker- en katoenteelt, niet genoegzaam evenwel om de kolonie als een landbouwende te behandelen; $2^{\circ}$. den handel met de naburige eilanden, inzonderheid met de Spanjaarden, ,welke in vredestijd van eenig gewicht kan zijn” $; 3^{\circ}$, en voornamelijk, in de zoutbereiding. Er bestaat aldaar ,een zeer groote zoutpan in dewelke, eens in order zijnde, een overvloedige quantiteit zout, hetwelk voor het beste in de West-Indiën gehouden wordt, zich verzamelt, zoodat dezelve op de millioen barrils ${ }^{1}$ ) om de drie jaren kan worden gesteld". Het zout wordt door de ingezetenen geraapt en tegen betaling van een recht van 2 schellingen per barrel uitgevoerd. Deze tak van bestaan kan de kolonie tot bloei brengen, ook hebben de meestgegoede ingezetenen hun fortuin aan de zoutoogsten te danken. Het bestuur wordt gevormd door een gouverneur, een Raad van eenigen uit de ingezetenen, een secretaris, fiscaal, boekhouder-generaal en eenige weinige beambten van lager rang. De bezetting bestaat volgens de laatste rapporten uit omtrent 100 man. Evenals St. Eustatius heeft ook St. Martin veel te lijden gehad door de contributie, de bevolking door de Fransche commissarissen in 1795 opgelegd en die eerst is opgehouden toen het eiland aan de Engelschen overging, die het na den vrede van Amiens in 1802 weder overgaven aan de Hollanders.

Op het eilandje Saba, een hooge, steil uit zee oprijzende berg, wonen omtrent 200 menschen, die van den landbouw leven. Uit dien berg zouden er „overvloedige zwavel, aluin en soortgelijke producten" kunnen worden gehaald zoo maar ,het acces niet zoo moeilijk was", doch „men heeft bevonden dat dit de onkosten nimmer heeft kunnen opwegen". Derhalve is het eiland alleen „als een dependentie van St. Martin door een vice-commandeur bestuurd geworden".

Curaçao heeft een ruwen, klippigen, onvruchtbaren bodem. „Het getal der blanke inwoners kan op 3 à 4000 , dat der vrije lieden van de couleur op 5 à 600 en dat der slaven op 16 à 18.000 geschat worden." De plantages zijn van wege de onvruchtbaarheid en den ongeregelden regenval nauwelijks meer dan 50 in getal, zoodat het eiland als landbouwkolonie van geen waarde is.

1) Een Engelsche barrel = ruim $163 \frac{1}{2}$ Liter. 


\section{MEMORIE OVER DE HOLLANDSCHE BEZITTINGEN.}

Doch van zeer groot belang maken het vooreerst zijn natuurlijke sterkte en zijn zeer ruime, welgelegen haven, een van de beste van de wereld en die, ook uit een militair oogpunt bezien, „voor een zeemogendheid, die in de West-Indiën geen andere haven bezit, van het uiterste gewicht is, te meer daar het eiland buitendien zeer sterk is, en de nationale garde, als tot bijna 1000 man kunnende gebracht worden, de uitzending van een groote bezetting van hier onnoodig maakt." Ten andere is Curaçao belangrijk door zijn ligging nabij de vaste kust ${ }^{1}$ ), die het geschikt maakt tot het drijven van handel. „De commercie, die aldaar met vreemde natiën en in het bijzonder met de Spanjaarden gedreven wordt, was zeer aanzienlijk en bestond in de verruiling van levensmiddelen, behoeften van allerlei aard en in het bijzonder van linnen en katoenen lijnwaten, die met Hollandsche schepen wierden aangebracht, tegen koffie, suiker, cacao, indigo, huiden, tabak, verfhout, ja zelfs parelen, gemunte Spaansche matten en gouden quadrupels, welke in vorige jaren de retouren voor 20 tot 30 groote schepen opleverden, doch waarvan wij het getal uit hoofde der vaart der Noord-Amerikanen, die thans zelve handel drijven, op niet meer dan van 12 tot 20 durven bepalen. Maar er is ook geen Hollandsche kolonie, die door de désastreuse omstandigheden der tijden zooveel geleden heeft als Curaçao, want na in het jaar 1795 een tooneel van partijschappen van allerlei aard en in het bijzonder ook van een factie, die op hetzelve de tooneelen van St. Domingo wilde aanrichten, geweest te zijn, is het in het jaar 1800 door eenige gewapende vaartuigen van Guadeloupe, die onder den schijn van vriendschap gekomen en van al het noodige voorzien waren - waarvan de door den commissaire Duny, van wege het Fransche gouvernement expresselijk naar de kolonie gezonden om deze zaak op te nemen, geverifieerde rekeningen onder ons berusten, - op de trouwelooste wijze behandeld geworden, heeft vervolgens zich aan de Engelschen moeten overgeven ten einde bevrijd te worden van het lot, hetwelk St. Domingo getroffen had, om hetwelk haar te doen ondergaan die expeditie beraamd was. In dezen oorlog heeft het in 1804 een hevig bombardement doorgestaan, is vervolgens bij continuatie door den vijand geblokkeerd gehouden en in het jaar 1805 aan verscheidene stroperijen, partiëele landingen, brandstichtingen en wegvoeringen van vee en slaven, met één woord.aan de gevolgen van dien kleineren oorlog geëxponeerd geweest, welke alle door het gouvernement en de brave ingezetenen met de meeste fermeteit zijn door-

1) Het tegenover liggende vasteland van Zuid-Amerika. 
MEMORIE OVER DE HOLLANDSCHE BEZITTINGEN. 393

gestaan of afgewend geworden". Maar dientengevolge verkeert Curaçao thans in een zeer armoedigen toestand en gaan de administratiekosten al de inkomsten zoo verre te boven, dat die in de laatste jaren 6 à 700,000 gulden hebben bedragen. Het gouvernement bestaat uit een gouverneur, een Raad uit 7 ingezetenen bestaande, een fiscaal, boekhouder-generaal en 2 secretarissen met de noodige mindere ambtenaren; echter kan de administratie in vredestijd aanmerkelijk vereenvoudigd worden en minder kostbaar gemaakt. Onder Curaçao hooren nog de eilanden Bonaire en Aruba. Bonaire, ongeveer even groot als Curaçao en alleen bewoond door eenige Indianen en vrije lieden van de couleur, levert hoofdzakelijk brandhout op, hetwelk Curaçao niet bezit, alsmede kalk en zout, doch kan bij den vrede op een beteren voet worden gebracht. Ook Aruba, dat van eenigen veehandel met deSpaansche kust bestaat en in zijn bosschen eenig verfhout opbrengt, schijnt voor verbetering vatbaar.

In de landbouwende koloniën Suriname, Berbice, Essequebo, en Demerary is het luchtgestel bijna hetzelfde als op de vaste kust, alleen maakt ,de meerdere of mindere opening van cultuur van moerassige gronden" deze of gene streek gezonder of ongezonder. Vast staat dat Suriname ,als ouder van aanleg en van zeer uitgebreide cultuur den voorrang heeft", en door velen gezonder wordt geacht dan St. Domingo ja zelfs dan Noord-Amerika, doordien de frissche zeewinden en de koelte der vele rivieren er de hitte temperen.

Een volledige schets te geven van den tegenwoordigen toestand van Demerary en Berbice is den Raad niet mogelijk. Men bedenke hoe zeer zich die in de laatste jaren heeft gewijzigd, en „dat wij sedert 1796 maar gedurende eenige weinige maanden in het bezit” dier koloniën ,zijn geweest ${ }^{1}$ ), terwijl vele van de depêches, die ons den staat der tegenwoordige populatie, getal, soort der plantagiën moesten doen kennen, in handen van den vijand zijn geraakt, en dat de Raad onkundig is welke veranderingen in de kolonie thans zijn gemaakt." Er kunnen derhalve van haar ,nauwelijks meer dan eenige zeer algemeene trekken opgegeven" worden. De bevolking van Demerary en Essequebo meent de Raad op 3 à 400 blanken te mogen stellen, het getal negers op 7000. De plantages verbouwen voornamelijk koffie, suiker en katoen, dit laatste was in Demerary vooral langs de zeekust zeer overvloedig. „Daar de zeekusten allerwege geopend zijn en op verscheidene plaatsen een zeer gemakkelijk acces geven is de kolonie weinig

1) Van 3 Dec. 1802 tot 17 (resp. 24) Sept. 1803. 


\section{MEMORIE OVER DE HOLLANDSCHE BEZITTINGEN.}

voor defensie vatbaar, althans niet zonder een groot aantal manschappen en oorlogsschepen, in den mond der rivier van Essequebo en Demerary geposteerd, te minder daar het fort Willem Frederik, aan de monden der rivier geplaatst, zeer aan afspoeling onderhevig is en op een andere plaats zou behooren te worden gelegd." De in 1802 derwaarts gezonden krijgsmacht, ten getale van omtrent 2000 man, is voor de bewaring der inwendige rust te groot, ,,voor de buitenlandsche defensie" te klein. De regeering is samengesteld uit een gouverneur-generaal, twee fiscaals en vier ingezetenen, alsmede uit een Raad van Justitie, bestaande uit den gouverneur, een adviseur en zes raden. Verder zijn er twee secretarissen, een boekhouder, een ontvanger-generaal en de noodige mindere beambten. De zeer lichte lasten, ,welke de ingezetenen tot hiertoe hebben betaald, bestaan hoofdzakelijk in een gering hoofdgeld en in zeer modique in- en uitgaande rechten, en verder uit eenige kleine belastingen, welke de helft der onkosten, die de kolonie in den korten tijd dat wij dezelve bezaten veroorzaakt heeft, niet (hebben) kunnen bestrijden, zoodat, wanneer de Raad in aanmerking neemt het groot vermogen der planters en hetgeen de ingezetenen in Suriname moeten opbrengen, die belastingen zonder eenigen hinder zullen kunnen en behooren te worden verhoogd". Het is derhalve niet het militaire punt maar dat der cultures, dat Essequebo en Demerary voor ons van zoo uitnemend groot gewicht doet zijn en tot een der aanzienlijkste koloniën maakt van de wereld. Van de uitbreiding der cultures ontvangt men eenig denkbeeld, wanneer men in het oog houdt „dat, daar in het jaar 1740 nauwelijks 1 of 2 schepen naar het vaderland met producten gezonden wierden, het getal in het jaar 1790, 91, 92 en 93 tot op tusschen de 40 à 50 was geaccresseerd, terwijl indien wij het geluk hadden mogen hebben om de retouren van het jaar 1802 in onze havens te zien binnenvallen, dat getal ruim 100 schepen zou bedragen hebben."

Dezelfde aanmerkingen gelden in hoofdzaak ook voor Berbice, dat „thans mede aan de zeekust geheel geopend en met Demerary thans vereenigd, weinig of geen defensie op zichzelf kan opleveren."

Behalve meer andere zaken heeft een verschrikkelijke slavenopstand in 1763 deze kolonie zeer „ondergehouden”, ook was het bestuur van vóór 1795 weinig geschikt om haar te doen bloeien, maar zij heeft zich weer opgebeurd en bezit thans ,een aanzienlijk getal" koffie-, katoen- en suikerplantages, en omtrent 20.000 slaven. Zij heeft in de jaren 1780 tot 1795 voortgebracht jaarlijks omstreeks 2.250 .000 pond koffie, 150.000 pond katoen, 100.000 
MEMORIE OVER DE HOLLANDSCHE BEZITTINGEN. 395

pond cacao en 350.000 pond suiker, en ,is sedert dien tijd met het verdubbeld getal van koffie en suiker (en de) dubbele waarde van katoen vermeerderd". De inrichting van het bestuur is in hoofdzaak dezelfde als in Demerary, nl. een gouverneur, een Politieke Raad van zes leden en een secretaris, tevens als fiscaal fungeerende, en een Raad van Justitie. De belastingen bestaan, behalve in in- en uitvoerrechten, in een hoofdgeld, een plantagegeld, een akkergeld en ,eenige andere kleine lasten".

Suriname is van 1667 tot 1798 in onze macht geweest, naar hetzelfde stelsel bestuurd en daardoor van lieverlede zeer in rijkdom en uitgebreidheid toegenomen. Van den toestand dezer kolonie, vóórdat de Engelschen haar in 1804 vermeesterden, valt te vermelden dat het getal inwoners bestond ,uit 4000 blanken, 700 vrije lieden van de couleur, waaronder 1000 Joden zoo blanken als vrijen, en 70 à 80.000 slaven". Het aantal plantages vóór 1798 beliep 500, „die thans meer dan 20 millioen kunnen opbrengen”, sedert zijn zij merkelijk vermeerderd en zullen dat nog meer zoo maar de aanvoer van slaven blijft voortduren, waaraan echter de Engelschen nu beletselen in den weg leggen. De regeering bestond uit een gouverneur-generaal, tevens hoofd van de militie en president van alle colleges; twee hoven, een van politie en crimineele justitie en een van civiele justitie; een college van kleine zaken, dat tot $f 250$ recht doet en van welks beslissingen appel valt op het hof van civiele justitie; twee fiscaals; een controleur-generaal van de magazijnen; twee secretarissen en verscheidene andere ambtenaren. De militie, onder bevel van een commandant die onder de orders van den gouverneur stond, telde bij de 2000 man. De kosten der kolonie beliepen, buiten die van de militie, tusschen de 3 à 4000 gulden, de inkomsten moeten op hetzelfde bedrag worden geschat. Thans loopen de kosten hooger maar kunnen ook de inkomsten worden verbeterd. Het getal der Hollandsche schepen, op die kolonie varende, kon op 70 à 80 worden gesteld. Het grootste gedeelte van de in cultuur zijnde plantages behoorde aan Hollanders, weshalve de handel van Suriname met het moederland aanzienlijker is dan die van Demerary en Berbice, waar vele landerijen aan Engelsche planters toebehooren. Het bedrag der negotiatiën, op de Surinaamsche plantages verhypothekeerd, zal 50 millioen bedragen ${ }^{1}$ ).

Aangezien de cultures er voor meerdere uitbreiding vatbaar zijn, moet Suriname voor het moederland „van een onbereken-

1) Zie over deze hypothecaire plantageleeningen de Encyclopaedie van Ned. West-Indië i. v. Negotiatiën. 


\section{MEMORIE OVER DE HOLLANDSCHE BEZITTINGEN.}

bare waarde worden gehouden". De staat van verdediging was voormaals in zeer goede orde, vermits de kusten van wege de bosschen ,inaccessibel" waren en men dus enkel het inkomen van de Surinamerivier behoefde te bemoeilijken, wat voornamelijk plaats had door eenige in de rivier geposteerde gewapende schepen en de kruisvuren van de forten Amsterdam, Leiden en Purmerend. Thans, nu die bosschen zijn weggehakt en de kust geopend is, ,is die defensie van minder nut, en zal het de eerste zorg van het gouvernement bij de terugbekoming der koloniën behooren te zijn dezelve naar de tegenwoordige situatie der kolonie te arrangeeren en daarnaar ook het getal der militie, derwaarts te zenden, te bepalen." In het algemeen dient ook aangemerkt te worden, ,dat daar Suriname bovenwinds van Demerary en de Berbice gelegen is, ook deze haar steunpunt in de defensiën dier kolonie vinden en dat, de kolonie van Suriname in een behoorlijken staat van defensie gebracht (zijnde), even daardoor die koloniën worden gesecureerd, en er weinige of geene kosten van dezelve tot dien einde zullen behoeven te worden gedaan."

Omtrent het bestuur van den Amerikaanschen Raad over de West-Indische koloniën wordt in de memorie het volgende medegedeeld.

Neemt men in aanmerking, dat die koloniën te voren onder drie afzonderlijke directiën stonden ${ }^{1}$ ), dan kan men ,reeds daaruit besluiten tot het verschil, hetwelk in dezelve in de wetten, zeden en gewoonten en de geheele wijze van bestaan, zelfs van die koloniën die langs dezelfde regels konden bestuurd worden, plaats heeft - een verschil hetwelk, hoezeer die diverse directiën thans vernietigd en alle de koloniën onder het bestuur van onzen Raad vereenigd zijn, echter thans in het wezen der koloniën bestaat en niet dan met vele voorzichtigheid zal kunnen worden weggenomen. Dit heeft des Raads administratie dikwijls niet weinig bemoeilijkt en veel omslachtiger gemaakt dan dezelve anders zoude zijn indien die bezittingen altijd onder hetzelfde bestuur gestaan hadden. Daar de zorg voor en het bestuur van al die bezittingen onverdeeld aan den Raad is opgedragen voert hij de correspondentie met de koloniën, bezorgt hun approvisionnement, beoordeelt de politieke, administratieve, militaire, finantiëele en huishoudelijke verrichtingen der gouverneurs (en) de geconstitueerde machten, die verplicht zijn hun journalen en notulen te dien einde over te

1) Nl. de West-Indische Compagnie, de Sociëteit van Suriname en de Directie van Berbice. In 1795 werden al onze West-Indische koloniën en de Kust van Guinee onder het rechtstreeksch bestuur van den Staat gebracht. 
MEMORIE OVER DE HOLLANDSCHE BEZITTINGEN. 397

zenden, zorgt voor de instandhouding en verbetering der defensie volgens het plan en systema door den souverein bepaald, zorgt bovendien dat de connexiën met het moederland bewaard, bevorderd en vermeerderd worden, heeft het opzicht over de cultuur in de landbouwende en over de handeldrijvende koloniën, doet voordrachten over het een en ander aan het gouvernement, met één woord de Raad heeft onder het opperbestuur van den souverein de administratie over de politie, de finantie, de cultuur, de handel en navigatie van elk der koloniën, voor zooverre daarin namelijk niet speciaal ${ }^{1}$ ) door het gouvernement zelve wordt voorzien, hetwelk ook door het gouvernement in de laatste jaren is geschied met opzicht tot de benoeming en verzending van militie naar de koloniën, waarvan de benoeming en alles wat tot de aanstelling, discipline en promotie der officieren relatie had door het ministerie van oorlog wordt bezorgd, en alles wat tot de kleeding, equipement en verzorging derzelve behoort door den Raad, gelijk ook het gouvernement zelf sommige hoogere ambtenaren heeft benoemd, waarvan de aanstelling anders te voren aan het koloniaal bestuur was opgedragen." Om „die wijduitgestrekte administratie” te kunnen voeren, beschikt de Raad over „middelen van gezag in de aanstelling, bevordering, suspensie, opontbod van de ambtenaren in de koloniën voor zooverre die niet directelijk door het gouvernement zijn aangesteld, en middelen van finantie in de perceptie en administratie van de recognitie- en lastgelden en andere belastingen, welke de commercie of planters tot soutien der koloniën en onkosten der administratie moeten opbrengen, gelijk mede uit hoofde der connexie der Noord-Amerikaansche commercie met die, welke directelijk op de koloniën gedreven wordt en geen diverse behandeling gedoogt, de administratie over die commercie aan den Raad is gedemandeerd, wordende alles in één kas, ten dienste der koloniën geaffecteerd en van 's Lands overige finantiën gesepareerd, verantwoord". Ofschoon de oorlog in 's Raads werkzaamheden een stremming teweeg brengt, blijft zijn administratie niettemin, ,zoo ten aanzien der overgebleven koloniën als binnenlandsche huishouding, belangrijk terwijl, hoezeer dezelve zich in militaire, finantiëele en mercantiele détails splitst, die détails alle uit één oogpunt - het belang der koloniën en (van het) moederland - moeten beoordeeld worden, waardoor diezelve geheel en al verschillen van de oogpunten, waaruit dezelfde objecten voor het moederland alleen beschouwd en behandeld worden."

(Volgt een breedvoerig vertoog over de algemeene voordeelen,

1) In het HS. staat: meer speciaal. 


\section{MEMORIE OVER DE HOLLANDSCHE BEZITTINGEN.}

welke de handel en vaart op de West-Indische koloniën aan het moederland toebrengen. Ik haal hieruit ten slotte nog aan de volgende zinsnede:)

„Wat dan de quantiteit en waarde der producten, die de koloniën jaarlijks aan het moederland opbrengen, aanbelangt, dezelve hebben in het jaar 1800 - de Raad bepaalt zich tot dat jaar vermits dat jaar geen der voordeeligste is geweest en de Raad daarvan de beste lijsten heeft - bestaan uit Demerary en Suriname uit 25.573.000 pond suiker, uit 28.645 .800 pond koffie en 10.229.500 (pond) katoen, dewelke tezamen op de waarde van bijna $f$. 31.000 .000 kunnen geschat worden." 